\title{
DECISION SUPPORT FOR RE-DESIGNED MEDICINAL PRODUCTS - ASSESSING CONSEQUENCES OF A CUSTOMIZABLE PRODUCT DESIGN ON THE VALUE CHAIN FROM A SUSTAINABILITY PERSPECTIVE
}

\author{
Siiskonen, Maria (1); Watz, Matilda (2); Malmqvist, Johan (1); Folestad, Staffan (3) \\ 1: Chalmers University of Technology; 2: Blekinge Institute of Technology; 3: AstraZeneca Gothenburg
}

\begin{abstract}
Despite advances in pharmacological research providing means for individually customized patient attribute treatments, the 'one-size-fits-all' paradigm remains. Customization is associated with cost increases and the value assessment of customized medicinal products shows upon a narrow economic focus. Inspired by value models, emerging in manufacturing industry research, this study suggests a novel methodology encompassing a full sustainability perspective, including the social, economic and ecological dimension, for design decision support for medicinal products. A concept screening matrix is adapted, using sustainability criteria as value indicators. The focus is to create value for the whole pharmaceutical value chain whilst keeping the core purpose of medicinal products, i.e. to bring societal benefits. An illustrative case study presents an application of the methodology on a commercial product for curing hypertension. The traditional product design for hypertension treatment is compared to a customized product design. Results indicate that a customized product design is preferable if value is to be created from a social or/and an ecological sustainability perspective.
\end{abstract}

Keywords: Personalized medicines, Product architecture, Sustainability, Sustainable product design, Decision making

Contact:

Siiskonen, Maria Daniela Irene

Chalmers University of Technology

Industrial and materials science

Sweden

maria.siiskonen@chalmers.se

Cite this article: Siiskonen, M., Watz, M., Malmqvist, J., Folestad, S. (2019) 'Decision Support for Re-Designed

Medicinal Products - Assessing Consequences of a Customizable Product Design on the Value Chain from a

Sustainability Perspective', in Proceedings of the 22nd International Conference on Engineering Design (ICED19), Delft,

The Netherlands, 5-8 August 2019. DOI:10.1017/dsi.2019.91 


\section{INTRODUCTION}

Advances in pharmacological research have provided opportunities for individually customized patient attribute treatments. These attributes can be categorized as biological, behavioural and environmental attributes (Crommelin et al., 2011). The current 'one-size-fits-all' paradigm in medicine production is challenged. Several attempts have had the ambition of redesigning the medicinal product to improve the customizability. For example, Siiskonen et al. (2018) developed a modularized product concept of oral dosage forms (ODF), more specifically a tablet. These modules provide different functionalities of the product to comply with the patients' attributes.

However, customization of medicinal products is commonly associated with various cost increases compared to traditional medicinal products due to e.g. new manufacturing technology investments as modularized tablet design requires additional assembly processes to provide an administrable product. Additionally, customization induces an increase in the number of stock-keeping units (SKU), leading to increased complexity in production and distribution - associated with increased cost (Lee et al., 2015). Research regarding cost-efficient customized treatments, such as that of Hatz et al. (2014) and Srai et al. (2015), shows a narrow focus not only being limited to an economic assessment of treatments, overshadowing the core purpose of medicinal products, i.e. treating people, but also a focus on the consequences of a specific phase of the pharmaceutical value chain. More focus is needed on finding medicinal product designs complying with this core purpose and in the end providing value for the whole value chain, for example by conducting a proper cost-benefit analysis.

Research on value-based decision support has emerged in the manufacturing industry, e.g. the aerospace industry, where a full sustainability perspective, i.e. including a social, economic and ecological dimension, has been adopted when assessing new products (Bertoni et al., 2015; Hallstedt et al., 2015). These value models result in a Net Present Value analysis and thus, require translation of criteria into monetary metrics. The concept screening matrix by Ulrich and Eppinger (2012), based on the concept selection method by Pugh (1990), is another value modelling approach where conceptual designs are comparatively related against a reference design, i.e. a translation into costs is not necessary.

To our best knowledge, no studies on product designs and the consequences for the pharmaceutical value chains, from a full sustainability perspective, have been conducted. Thus, inspired by above-mentioned value models, the aim of this research is to address this gap by proposing a novel methodology to support decisions for re-designed medicinal products, more specifically ODF, which is the most common dosage form today (Nagashree, 2015). The ODF is re-designed to embrace a higher level of customization than traditional product designs and the consequences for the value chain are assessed from a full sustainability perspective. The focus is to create value for the pharmaceutical value chain whilst bringing societal benefits. The study adopts the value assessment approach by Ulrich and Eppinger (2012), i.e. concepts are related benefit-wise to a reference concept with respect to chosen criteria. Thus, a concept screening matrix is adapted, allowing the assessment of product concepts using sustainability criteria as value indicators. The research question is 'How is the value chain affected from a sustainability perspective due to an introduction of customized product design?' An illustrative case study is performed to test the methodology on a commercial product for hypertension treatment. The traditional product design is compared to a customizable product design. The theoretical contribution of this study is a methodology to develop and assess new medicinal product designs, integrating a full sustainability value perspective. The practical contribution is a proposal for how to design a medicinal product to increase product value. The remaining paper is organized as follows: Section 2 outlines the research approach and Section 3 presents the novel methodology. Section 4 describes an illustrative case study to present the application of the methodology. The results from the illustrative case study are presented in Section 5 and discussed in Section 6 jointly with a discussion of the developed methodology. Section 7 concludes the paper and describes future work.

\section{RESEARCH APPROACH}

A sequence of research activities was conducted to address the perceived research gap. First, theory developing studies were conducted to develop a methodology for decision support. These studies included the adoption of a previous study by Siiskonen et al. (2018) to establish a customized product concept (CPC). A qualitative sustainability assessment tool, SLCA2.0 (Villamil et al., 2018), was chosen to estimate sustainability performance of such an ea phase design, from a full sustainability perspective. The sustainability performance of the traditional product concept (TPC) was benchmarked in parallel with the 
aid of established literature and expert knowledge, i.e. researchers in value-driven design and sustainable product development, informed by literature and an expert with detailed knowledge about the industrial case. From literature studies, the value chain of a pharmaceutical product (Aitken, 2016) and the variables prone to be affected due to a change in product design were clarified. Finally, the concept screening matrix by Ulrich and Eppinger (2012) was adapted to enable simulations providing quantitative data on a value comparison of CPC to TPC. Secondly, an illustrative case study was performed to illustrate the application of the developed methodology. A commercial product for curing hypertension was chosen for the illustrative case study.

\section{PROPOSED METHODOLOGY}

To make a value assessment of medicinal products from a sustainability perspective, a methodology is presented in this section. Figure 1 outlines the proposed methodology composed of various parallel and interconnected activities and a description of the activities is provided in the succeeding sections. Section 3.1 describes a sustainability assessment of medicinal products, adaption and execution of the product platform of CPC and describing and qualitatively comparing the TPC and the CPC according to sustainability performance variables (SPVs). Information from the qualitative comparison is used for consequence analysis on the value chain of pharmaceutical products, which is described in Section 3.2. The value chain assessment is quantified into a value model in Section 3.3 to calculate the relative value of the CPC to the TPC.

\subsection{Sustainability lifecycle assessment of medicinal products}

A sustainability assessment is conducted using SLCA2.0 (Villamil et al., 2018). The sustainability performance of respective product design, the CPC and TPC, is qualitatively assessed from a full sustainability perspective. SLCA2.0 applies backcasting from eight sustainability principles (SPs), corresponding to anthropogenic mechanisms of ecological- (SP 1-3) and social system destruction (SP 48), which are described in detail in the Framework for Strategic Sustainable Development (Broman and Robért, 2017). In this study, a comparative SLCA (Villamil et al., 2018) is conducted, following the general guidelines for a comparative LCA as described in ISO 14001. The two final steps of SLCA2.0 are followed with the aim to qualitatively compare the CPC with the TPC. Templates and guiding questions, summarized in Figure 2, inform each step and this information is complemented by additional literature as well as expert knowledge since this is the first application of the method on a medicinal product. The SPs translate into SPVs and are used to describe the CPC and the TPC. The SPVs originates from the guiding questions shown in Figure 2. The relevant set of questions are chosen by the researchers according to topics found in previous literature conducting sustainability assessments of medicinal products, such as Slater et al. (2007) and Sheldon (2016). Since the literature shows upon a narrow focus on the ecological sustainability dimension, the researchers chose additional questions according to their best judgment. The guiding questions for this study are shown in bold in Figure 2.

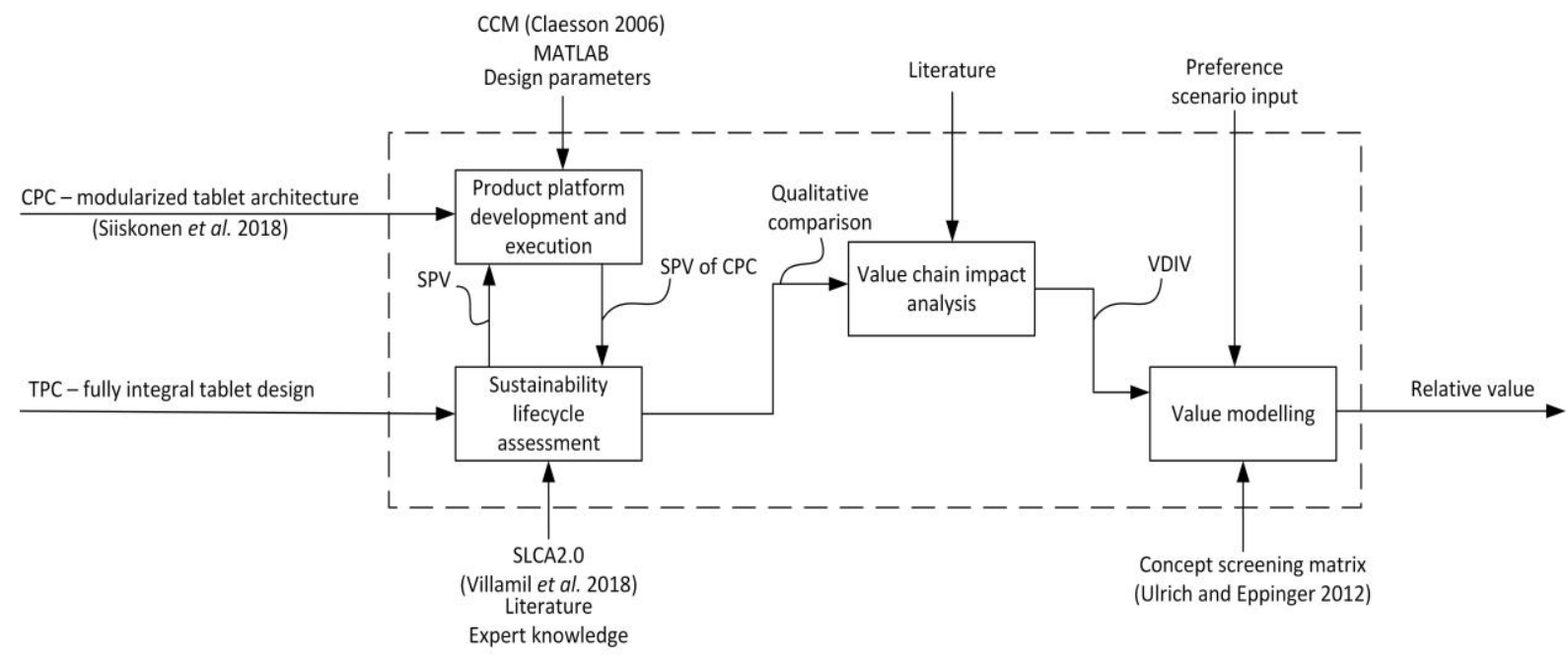

Figure 1. The proposed methodology to support design decisions of medicinal products 

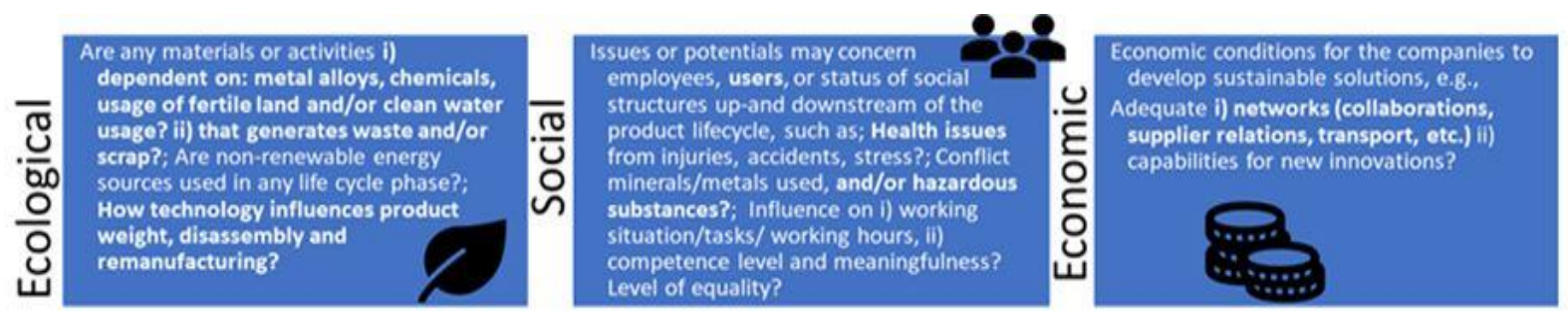

Figure 2. Adopted guiding questions per sustainability dimension (Villamil et al., 2018).

To enable a comparison of the CPC to the TPC, the SPVs need to be transformable into measurable units. SPVs can be of both quantitative, e.g. material consumption and number of SKUs, as well as of qualitative nature, e.g. usage and end-of-life fate.

\subsubsection{Product platform development and execution}

To describe a CPC according to SPVs, a customized product design is established adopting an approach developed by Siiskonen et al. (2018). Based on the Configurable Component (CC) framework (Claesson, 2006), this platform approach builds on functional modelling to structure the product according to its functional requirements (FR). The FRs are established from a translation of patient attributes to various design parameters. Design solutions (DSs) are provided to FRs, and these are encapsulated as independently functioning configurable components (CC). Constraints (Cs) are used for potential restrictions of functional regions. This model forms the product architecture, i.e. the product platform foundation.

The platform modelling software CCM (Claesson, 2006) is used for modelling and execution of the product platform, generating sets of product variants grounded in the product architecture of CPC. Note that CPC is a concept grounded in one product architecture but due to scalable properties of the CC-objects, sets of product variants can be established. The CCM software is limited to solving a full factorial combinatorial problem and has no inherent function to eliminate unfeasible solutions. Thus, sets of configured product variants are imported into MATLAB to eliminate unfeasible solutions and to quantify the SPVs of the CPC.

\subsection{Value chain impact analysis}

To assess the overall value created from introducing a CPC, the value chain of a pharmaceutical product is studied with the aim of identifying which phases, the variables of these phases, and how the value of these variables would be affected. The effects are studied by analysing the SLCA2.0 results and complemented by manufacturing performance-related information by Srai et al. (2015) and Harrington et al. (2017). The variables are called value driving impact variables (VDIV) and are categorised according to the sustainability dimension (SD) affected. The value change is stated for each variable.

Figure 3 presents an illustration of the pharmaceutical value chain by Aitken (2016). The value chain is assumed to remain in the current paradigm, but a customized product design is introduced into it. The pharmaceutical value chain consists of three phases, manufacturing of the medicinal product, delivery to dispensing point and dispensing to end user. The manufacturing phase includes activities from research and development to regulatory approval and commercial production (Food and Drug Administration, 2018). Commercial production of medications is divided into primary production, where the raw material for the medication is produced, and into secondary production, the phase during which the final medicinal product is produced. The purpose is to connect product design with manufacturing performance and to succeeding phases i.e. delivery to dispensing point and dispensing to end user and studying the propagation of consequences due to a change in product design. Thus, initial research and regulatory considerations are outside scope. Additionally, the raw material produced, primary production, is assumed to remain static and hence be independent of product design.

\begin{tabular}{|c|c|}
\hline $\begin{array}{c}\text { Manufacturing of } \\
\text { medicinal product }\end{array} \rightarrow \begin{array}{c}\text { Delivery to the } \\
\text { dispensing point }\end{array} \rightarrow \begin{array}{c}\text { Dispensing to } \\
\text { end user }\end{array}$ \\
\hline
\end{tabular}

Figure 3. Traditional pharmaceutical value chain adopted from Aitken (2016). 


\subsection{Value modelling}

Value modelling is employed for systematic product design decisions. A value function is developed adapting the concept screening matrix by Ulrich and Eppinger (2012). This matrix will provide a quantitative number of the relative value of the CPC compared to TPC. The aim is to find the most valuecreating product design. The resulting value function is presented in Equation (1).

$$
U=w_{\text {social }}\left(\frac{\sum v d i v_{\text {social }}}{i}\right)+w_{\text {ecological }}\left(\frac{\sum v \text { div } v_{\text {ecological }}}{j}\right)+w_{\text {economic }}\left(\frac{\sum v d i v_{\text {economic }}}{k}\right)
$$

$U$ is the relative value of the CPC compared to the TPC. The respective $w$ 's are weights of each sustainability dimension and are varied to emphasise various preferences. For example, if a product concept performing well from a social sustainability perspective is desired, the weight of this dimension is given a higher quantity. The respective $v d i v$ 's describe the value change of VDIVs. The vdiv's for each sustainability dimension are summarized and normalized with respect to the number of VDIVs, $i, j$ and $k$ , that each dimension embed.

\section{ILLUSTRATIVE CASE STUDY}

A commercial medicinal product is used to test the proposed methodology described throughout Section 3. This product is aimed at curing hypertension. Unmanaged hypertension can lead to heart attack and stroke (MacGill, 2018). The product chosen adopts the dosage form of a tablet. The TPC follows the subsequent assumptions; the product design embraces a fully monolithic, i.e. integral product design and embeds a single active pharmaceutical ingredient (API). The function of an API is to provide a therapeutic effect in the body. The API density is $1.4 \mathrm{~kg} / \mathrm{mm}^{3}$. The treatment today is offered in three variants and is described according to API content, 2.5, 5 and $10 \mathrm{mg}$. These product variants have a flat-faced cylinder shape with a diameter of $8 \mathrm{~mm}$ and height of $2.5 \mathrm{~mm}$; hence, the resulting volume of each variant becomes $126 \mathrm{~mm}^{3}$. Additionally, the tablet embeds excipients, lactose and hydroxypropyl methylcellulose (hypromellose), in the 20:80 ratio, and provide the tablet with functions to provide material and modifying the release of API, respectively.

The CPC is assumed to embrace a modularized tablet design consisting of two different types of modules. The function of the first module type is to provide a therapeutic effect and embeds $0.1 \mathrm{mg}$ API. The API is the same as for the TPC. The drug loading of the modules is $30 \%$ and the remainder is assumed to consist of excipients, the same as in the TPC. The second module has a function to provide material and modify the release of API and contains $10 \mathrm{mg}$ excipients. The geometrical volumes of the product variants of CPC range from $4 \mathrm{~mm}^{3}$, the size of a preferred medication for children assuming a tablet height of $1 \mathrm{~mm}^{3}$ (Klingmann et al., 2013), to $126 \mathrm{~mm}^{3}$, i.e. the volume of the TPC.

The treatment of the patient population is assumed to follow a normal distribution. The dosage need covers the interval from 2.5 to $10 \mathrm{mg}$, and $99.7 \%$ of the treatment need is assumed to fall inside 2.5 and $10 \mathrm{mg}$. The patient population is generated by using a normal random number generator in MATLAB. One thousand simulations were performed to provide an average population. The treatment of the population with TPC is assumed to be performed in a surplus manner to ensure sufficient dosage; patients requiring a dose i) of $2.5 \mathrm{mg}$ or less are offered a product variant of size $2.5 \mathrm{mg}$, ii) larger than $2.5 \mathrm{mg}$ but less than or equal to $5 \mathrm{mg}$ are offered a product variant of $5 \mathrm{mg}$, iii) larger than $5 \mathrm{mg}$ are offered a product variant of $10 \mathrm{mg}$.

The treatment of the population with the CPC is performed by offering a dose between 2.5 and $10 \mathrm{mg}$, with a dose step of $0.1 \mathrm{mg}$ (the size of API module). The number of filling modules in each product variant of the CPC follows the assumption; for each dose step that a product variant is configured, product variants exist that are equal with regard to dose but different with regard to the number of filling modules. These product variants, equal in dose content, cover the whole range of product variants when the number of filling modules is varied (inside the allowed product volume region). These variants for respective dosages are assumed to be configured in equal quantities.

The relative value of the CPC compared to TPC is assessed in simulations, where various scenarios, see Table 1, undertake different values on respective $w$ in Equation (1). The respective $v$ div's of the CPC are quantified in the following manner: if the value of a VDIV is increased when introducing the CPC the vdiv is set to +1 and if the value decreases the vdiv is set to -1 , an unchanged value is quantified as 0 . 
Table 1. Scenarios prepared to assess the relative value of the CPC.

\begin{tabular}{|l|l|l|l|l|l|l|}
\hline Scenario & $\mathbf{1}$ & $\mathbf{2}$ & $\mathbf{3}$ & $\mathbf{4}$ & $\mathbf{5}$ & $\mathbf{6}$ \\
\hline$w_{\text {social }}$ & 0.67 & 0.67 & 0 & 0.33 & 0.33 & 0 \\
\hline$w_{\text {ecological }}$ & 0.33 & 0 & 0.67 & 0.67 & 0 & 0.33 \\
\hline$w_{\text {economic }}$ & 0 & 0.33 & 0.33 & 0 & 0.67 & 0.67 \\
\hline
\end{tabular}

\section{RESULTS FROM THE ILLUSTRATIVE CASE STUDY}

This section presents the results from the illustrative case study described in Section 4.

\subsection{Sustainability performance assessment of a customized product design}

Figure 4 shows the architecture of a customized product design for hypertension treatment. The physical realization of the product is a modularized tablet design. The FR on the highest hierarchical level is provide treatment and realized through the DS tablet. The DS tablet is constrained by size, more specifically volume. The tablet is further expressed in sub-FRs that the tablet embeds, treat disease, provide suitable size and provide sustained release. Note that the FRs provide suitable size and provide sustained release are conceptually realized as a common DS, filling modules, hence the physical realization of these FRs are in the same modules.

The DS API module to the FR treat disease is scalable regarding the number of modules in a product variant. Thus, the platform execution generates a set of product variants consisting of various numbers of modules. These product variants cover each dosage in-between 2.5 and $10 \mathrm{mg}$, with a dose step of $0.1 \mathrm{mg}$. Likewise, the DS filling modules is scalable according to the number of modules. Varying the number of filling modules provides different sizes of tablets to facilitate administration, which is a known difficulty (Food and Drug Administration, 2015). Additionally, opportunities to tamper with the tablets release properties arise, which are dependent on the size and shape of a tablet (Goyanes et al., 2015). How the release rate is affected is outside the scope of this study.

\subsubsection{Sustainability performance variables}

The execution of the product platform results in measurable SPVs for the CPC. These SPVs are listed in Table 2. Likewise, the SPVs of the TPC have been listed for comparison and follows the assumptions presented in Section 4. As mentioned, the TPC is offered in three variants and an average amount of material consumption is presented. The CPC platform provides 76 feasible product variants by platform execution inside the feasible volume range 4 to $126 \mathrm{~mm}^{3}$. These product variants are described in the number of modules and module sizes, hence the material consumption of variants is calculated from this data. The average material consumption of the whole set is used to enable comparisons.

Product design change is the focus of study, hence succeeding life-cycle phases are adopting the nature of the current paradigm. Changes to succeeding phases are logically concluded. For example, an additional assembly process is required to configure an administrable product from modules, the usage of a customised dosage of API is assumed thus, minimizing leftovers during end-of-life and no changes occur to package recycling.

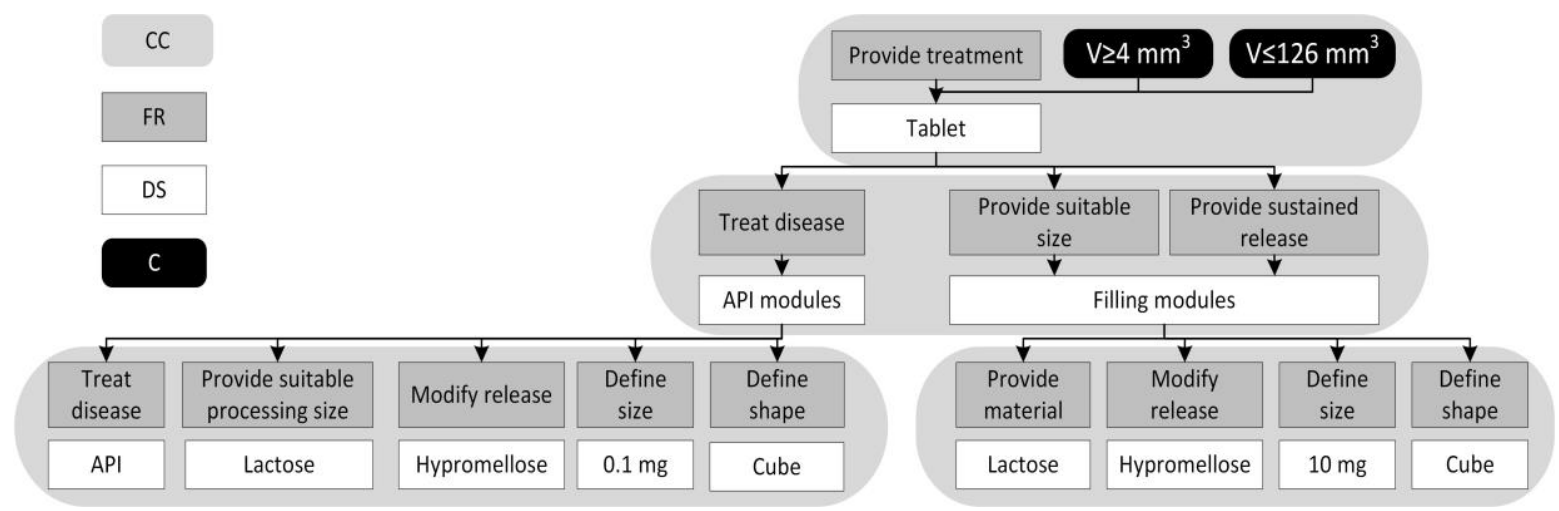

Figure 4. The architecture of the CPC. Adapted from Siiskonen et al. (2018). 
Table 2. SPVs, derived from the SLCA, for the TPC and a CPC.

\begin{tabular}{|c|c|c|}
\hline SPV & TPC & CPC \\
\hline $\begin{array}{l}\text { Design: Nature of } \\
\text { design and } \\
\text { dimensions }\end{array}$ & $\begin{array}{l}\text { Monolithic design with form of a cylinder } \\
\text { with flat faces, } h=2,5 \mathrm{~mm} ; p=8 \mathrm{~mm} \text {; } \\
V=126 \mathrm{~mm}^{3}\end{array}$ & $\begin{array}{l}\text { Modularized design with various forms; } \\
\text { Various sizes; Volume range }=[4,126] \mathrm{mm}^{3}\end{array}$ \\
\hline $\begin{array}{l}\text { Raw material: } \\
\text { amount, absolute, } \\
\text { average[mg/unit] }\end{array}$ & $\begin{array}{l}\text { API: } 2.5 ; 5 ; 10- \\
\text { Excipients: } 175.4 ; 172.9 ; 167.8 \\
\text { Average: API: } 8.2 \text { - Excipients: } 169.6\end{array}$ & $\begin{array}{l}\text { API: } 2.5 \text { to } 10 \text { - Excipients: Varying amounts, } \\
\text { scalable property } \\
\text { Average: API: } 6.2 \text { - Excipients: } 90.7\end{array}$ \\
\hline $\begin{array}{l}\text { Manufacturing: } \\
\text { Technologies }\end{array}$ & $\begin{array}{l}\text { Traditional dry powder mixing and } \\
\text { compressing in a batch process; } \\
\text { (1 manufacturing line, } 2 \text { change-overs) }\end{array}$ & $\begin{array}{l}\text { Traditional dry powder mixing, compressing in } \\
\text { a batch process; } \\
(1 \text { line }+1 \text { change-over, flexible press }) ;+ \\
\text { assembly process }\end{array}$ \\
\hline Distribution: & $3 \mathrm{SKU}$ & $76 \mathrm{SKU}$ \\
\hline Use: & $\begin{array}{l}\text { User provided with a package of standard } \\
\text { dosage of API }\end{array}$ & $\begin{array}{l}\text { User provided with a customised dosage of } \\
\text { API }\end{array}$ \\
\hline End of life: & $\begin{array}{l}\text { Ideally return leftover doses to recycling/ } \\
\text { waste treatment, Package to } \\
\text { recycling/landfill }\end{array}$ & $\begin{array}{l}\text { Ideally no leftovers } \\
\text { Package to recycling/landfill }\end{array}$ \\
\hline
\end{tabular}

\subsubsection{Qualitative sustainability performance comparison}

The qualitative comparison of results in Table 2 are as follows; in the raw material extraction and processing phase, the use of chemicals and solvents, the use of fossil energy and intensive water consumption are examples of issues for the TPC, and a decreased total demand of resources can be expected for the CPC (Slater et al., 2013). In the social dimension, it is likely to encounter issues with work conditions for the TPC, and no change can be expected for the CPC. In the economic dimension, the TPC is associated with challenges concerning various costs for resources and operations, which are likely to decrease for the CPC as a result of a decreased total demand of resources (Slater and Savelski, 2007; Sheldon, 2016). A CPC, based on the assumption that a reduction in material processing is expected, may lead to a reduction of emissions, wastes and water consumption (Unger, 2013; Sheldon, 2016). The social dimension may be associated with workplace challenges in the form of risks for chemical exposure and repetitive work for the TPC (Segawa et al., 2016; Savoia et al., 2017), and no change can be expected for the CPC. The economic dimension is associated with costs for material and operations for the TPC, and increased costs may be expected due to the need of investments in new technology and additional assembly process, and adjustment of information on packages. However, increased innovation capabilities due to the best available technology can be an opportunity.

The distribution phase for the TPC is associated with fossil fuel use and emissions in ecological dimension, which are likely to increase for the CPC due to increased complexity as multiple variants are introduced (Srai $e t$ al., 2015). No difference can be expected between the TPC and CPC in the social dimension. The increased complexity may, however, induce increased costs for the CPC compared to the TPC in the economic dimension. In the use phase, no difference is expected in ecological performance. In the social dimension, the CPC inducing an increased treatment quality is expected (Savoia et al., 2017), but consequently an increased price compared to the TPC. In the economic dimension, an increased price can be problematic from a market attractiveness perspective (Nicholson Price and Rai, 2015).

At the end of life phase, the TPC is associated with linked environmental challenges, including emissions of chemical substances to water and soil, as well as waste management practices of material packaging and surplus dosages (Srai et al., 2015). These challenges are all likely to be decreased for the CPC. In the social dimension, less risk for challenges associated with chemical exposure and societal costs for waste management is expected. The economic dimension is unlikely to change.

\subsection{Value chain impact analysis and value modelling}

Table 3 summarizes the results from the comparative sustainability assessment and the value chain impact analysis. For each value chain phase, respective VDIVs are listed and categorized according to SD, Eecological, S-social and \$-economic. The CPC is compared to the TPC for each VDIV in each SD. If a VDIV increases, decreases or remains the same (or the change is unknown) with respect to value, the CPC scores a “+”,"-" or "0", respectively. 
Table 3. The VDIV for each value chain phase and the relative value change.

\begin{tabular}{|c|c|c|c|c|c|}
\hline \multirow[t]{2}{*}{ Value chain phase } & \multirow[t]{2}{*}{ Value driving impact variable } & \multirow[t]{2}{*}{ TPC } & \multicolumn{3}{|c|}{$\mathrm{CPC}$} \\
\hline & & & $\mathrm{E}$ & $\$$ & $\mathrm{~S}$ \\
\hline \multirow[t]{4}{*}{ Secondary production } & Raw material consumption & $\mathrm{R}$ & + & + & \\
\hline & Solvent consumption & $\mathrm{E}$ & 0 & 0 & \\
\hline & Investments & $\mathrm{F}$ & & - & \\
\hline & Inventory & $\mathrm{E}$ & & + & \\
\hline \multirow{3}{*}{$\begin{array}{l}\text { Delivery to } \\
\text { dispensing point }\end{array}$} & Transportation & $\mathrm{R}$ & - & - & + \\
\hline & Packaging cost & $\mathrm{E}$ & & - & \\
\hline & Inventory & $\mathrm{N}$ & & + & \\
\hline \multirow{5}{*}{$\begin{array}{l}\text { Dispensing to end } \\
\text { user }\end{array}$} & End-of-life waste & $\mathrm{C}$ & + & & \\
\hline & Unit cost & $\mathrm{E}$ & & - & - \\
\hline & Administration effort & & & & + \\
\hline & Release properties & & & & + \\
\hline & Side effects & & & & + \\
\hline
\end{tabular}

The results in Table 3 are quantified and plotted for each scenario prepared in Table 1, see Figure 5. For scenarios emphasising social and ecological sustainability, i.e. Scenario 1 and 4 , the preferred product design is the CPC. In Scenario 2, where the major emphasis is placed on the social dimension and the second major on the economic dimension, the CPC will still perform better than the TPC value-wise.

\section{DISCUSSION}

This study has proposed a methodology to conduct value assessments of medicinal products from a sustainability perspective. The selection of guiding questions by Villamil et al. (2018) for the sustainability lifecycle analysis brings difficulty in reproducing the study. The relevant guiding questions for the topic studied has been completely decided by previous experiences, literature, knowledge and interpretations of the researcher. Hence, SPVs describing the TPC and the CPC can be highly varied depending on the researcher performing the study. Future work should include comprehensive studies regarding the selection of the set of guiding questions for medicinal products.

Overall, the proposed methodology is transferable to other products and performed by adapting the product platform to a desired product concept. The transferability to other ODFs, e.g. capsules or liquids, is conducted by adjusting the functioning bandwidths of product platform presented in Figure 4. The methodology can also be applied to medical devices, for instance, an insulin delivery device. An insulin delivery device would consist of insulin and a device providing the means of administering the insulin. The architecture of the insulin delivery device can be established by adjusting the architecture of tablet, see Figure 4 . The treat disease FR on the second hierarchical level can be solved by the API system DS (referring to insulin in a realizable form). On the lowest hierarchical level, various types of insulin can be generated by introducing bandwidths to the DSs. Further, the provide suitable size FR can be generally expressed as provide convenient drug delivery, hence expanding the functional bandwidth beyond a tablet. Thus, the FR can be solved by the insulin delivery device DS and physically realized as various types of devices. Platform execution generates various insulin - insulin delivery device variants and the compatibility to patient attributes can be increased through medication adherence. The number of successful treatments can increase and the value of VDIVs in the social and economic SD. Poor adherence of diabetes medication has shown to be a major cost for health care due to for example hospitalisations (Ho et al., 2006).

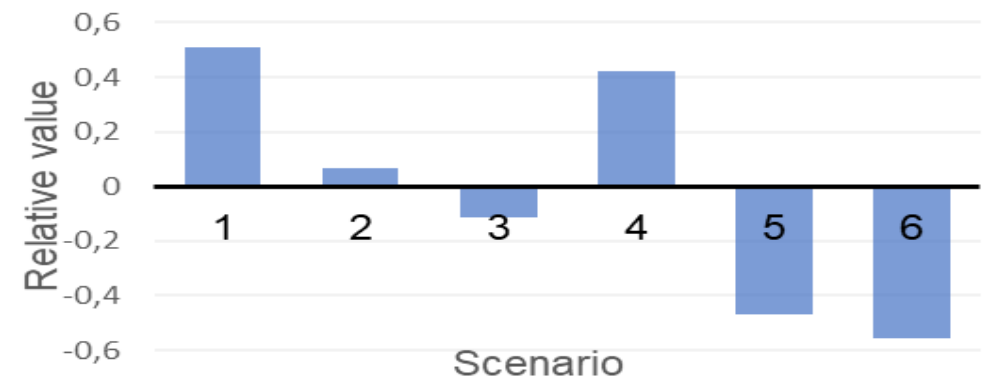

Figure 5. Relative value of CPC compared to TPC for each scenario prepared in table 1. 
Revisiting the research question 'How is the value chain affected from a sustainability perspective due to an introduction of customized product design?' can be stated that in the value chain, value is created for scenarios emphasizing social and environmental sustainability. An introduction of a CPC leads to reduced API consumption and reduced side effects because of an elimination of surplus dosing. Surplus dosing with the TPC is an assumption and the API consumption can be overestimated. Excipient consumption decreases due to the scalability of the number of filling modules and constraining the maximum product volume of the CPC.

A flexible size and shape are assumed to decrease administration effort and enhance release properties. The freedom of scaling the number of filling modules, covering the whole feasible product variant volume range, is considered a valid opportunity. The sizes of the TPC variants are the same regardless of dose content and hence, it is assumed that the API to excipient ratio is not optimized for the TPC. A traditional production process is assumed to remain the same but the adjustability of a tablet press to the considerably smaller module size of a CPC is not verified and need further investigation. Further, solvent consumption needs to be studied when elaborate studies on production processes are performed.

The CPC is assumed to better match the medication demand, which entails a shift from a high to low inventory environment, both in the secondary production- and delivery phase. This shift increases value from an economic perspective. The unit cost of the CPC will increase, hence becoming less affordable and value destructive from a social perspective.

Each VDIV in the value model is judged equally important within an SD. A comparison regarding the better or worse performance of the CPC to the TPC is provided but the magnitude is not given. Thus, scales to rate the VDIVs according to should be implemented.

For the respective SDs, the VDIVs are judged equally important, e.g. the VDIV unit cost and reduction of side effects, in the social dimension, are both given the same absolute quantity. A patient might have a higher willingness to pay for a product eliminating side effects, which should be emphasized more. Thus, internal weightings should be introduced.

\section{CONCLUSIONS AND FUTURE WORK}

The proposed methodology shows that a value-driven approach can be used to support systematic decisions regarding medicinal product designs. The methodology adopts a full sustainability perspective and provides opportunities to study effects on the whole value chain of pharmaceutical products. However, conducting the sustainability performance assessment of product concepts is highly governed by researchers' experiences, knowledge and available literature, hence complicating the reproducibility of the study. Future studies on sustainability performance criteria of medicinal products need to be conducted. Additionally, this method will be expanded in the future to enable the assessment of various new product concepts on more elaborate quantitative scales. Furthermore, internal weightings of VDIVs in respective sustainability dimension should be introduced to emphasise VDIVs considered to be more important. The proposed methodology can be transferred to products beyond the ODF, shown conceptually on a medical device.

Data show that: A CPC is preferable if value is to be created from a social or/and an environmental sustainability perspective.

\section{REFERENCES}

Aitken, M. (2016), "Understanding the pharmaceutical value chain”, Pharm Policy and Law, Vol. 18 No. 1-4, pp. 5566. http://doi.org/cxzc

Bertoni, M., Hallstedt, S. and Isaksson, O. (2015), "A model-based approach for sustainability and value assessment in the aerospace value chain", Adv Mech Eng, Vol. 7 No. 6, pp. 1-19. http://doi.org/f3pnrf.

Broman, G.I. and Robért, K-H. (2017), “A framework for strategic sustainable development”, J Cleaner Prod, Vol. 140 No. 1, pp. 17-31. https://doi.org/10.1016/j.jclepro.2015.10.121.

Claesson, A. (2006), "A Configurable Component Framework Supporting Platform-Based Product Development", Doctoral Thesis, Department of Product and Production Development, Chalmers University of Technology, Gothenburg.

Crommelin, D.J.A., Storm, G. and Luijten, P. (2011), “'Personalised medicine' through 'personalised medicines': Time to integrate advanced, non-invasive imaging approaches and smart drug delivery systems", Int J Pharm, Vol. 415 No. 1-2, pp. 5-8. http://doi.org/fr4thx.

Food and Drug Administration. (2015), Size, Shape, and Other Physical Attributes of Generic Tablets and Capsules Guidance for Industry.

Food and Drug Administration. (2018), Step 3: Clinical Research. 
Goyanes, A., Martinez, P.R., Buanz, A., Basit, A.W. and Gaisford, S. (2015), "Effect of geometry on drug release from 3D printed tablets", Int J Pharm, Vol. 494 No. 2, pp. 657-663. http://doi.org/f7vm6f.

Hallstedt, S.I., Bertoni, M. and Isaksson, O. (2015), “Assessing sustainability and value of manufacturing processes: a case in the aerospace industry", J Cleaner Prod, Vol. 108, pp. 169-182. http://doi.org/f3pz7z.

Harrington, T.S., Phillips, M.A. and Srai, J.S. (2017), "Reconfiguring global pharmaceutical value networks through targeted technology interventions", Int J Prod Res, Vol. 55 No. 5, pp. 1471-1487. http://doi.org/cxr7.

Hatz, M.H.M., Schremser, K. and Rogowski, W.H. (2014), "Is individualized medicine more cost-effective? a systematic review”, PharmacoEconomics, Vol. 32, No. 5, pp. 443-455. http://doi.org/f53wq6.

Ho, P.M., Rumsfeld, J.S., Masoudi, F.A., McClure, D.L., Plomondon, M.E., Steiner, J.F. and Magid, D.J. (2006), "Effect of medication nonadherence on hospitalization and mortality among patients with diabetes mellitus", Arch Intern Med, Vol. 166, pp. 1836-1841. http://doi.org/dwhzz4

Klingmann, V., Spomer, N., Lerch, C., Stoltenberg, I., Frömke, C., Bosse, H.M., Breitkreutz, J. and Meissner, T. (2013), "Favorable acceptance of mini-tablets compared with syrup: a randomized controlled trial in infants and preschool children", J Pediatrics, Vol. 163, pp. 1728-1733. http://doi.org/f2nzbt.

Lee, S.L., O’Connor, T.F., Yang, X., Cruz, C.N., Chatterjee, S., Madurawe, R.D., Moore, C.M.V., Yu, L.X. and Woodcock, J. (2015), "Modernizing pharmaceutical manufacturing: from batch to continuous production", $J$ Pharm Innov, Vol. 10 No. 3, pp. 191-199. http://doi.org/cxr8.

MacGill, M. (2018), Everything You Need to Know about Hypertension. Available at: https://www.medicalnewstoday.com/articles/150109.php (Accessed: 4 December 2018).

Nagashree, K. (2015), "Solid dosage forms: Tablets”, J Pharm Analysis, Vol. 4. No. 2

Nicholson Price, W. and Rai, A.K. (2015), "Manufacturing barriers to biologics competition and innovation", Iowa Law Review.

Pugh, S. (1990), Total Design: Integrated Methods for Successful Product Engineering, Addison-Wesley, Wokingham.

Savoia, C., Volpe, M., Grassi, G., Borghi, C., Agabiti Rosei, E. and Touyz, R.M. (2017), "Personalized medicine — a modern approach for the diagnosis and management of hypertension", Clinical Science, Vol. 131 No. 22, pp. 2671-2685. http://doi.org/cxr9.

Segawa, A., Yoshikawa, S., Toyama, T., Nakanishi, H., Kikuchi-Uehara, E., Hirao, M. and Sugiyama, H. (2016), "Method for reducing environmental, health, and safety risks in active pharmaceutical ingredient manufacturing based on multiobjective evaluation", Process Safety and Environmental Protection, Vol. 104, pp. 304-313. http://doi.org/cxsb.

Sheldon, R.A. (2016), "Green chemistry and resource efficiency: towards a green economy”, Green Chem, Vol. 18 pp. 3180-3183. http://doi.org/cxsc.

Siiskonen, M., Folestad, S. and Malmqvist, J. (2018), “Applying function-means tree modelling to personalized medicines", In Proceedings of NordDesign 2018, Linköping, 14th-17th August 2018

Slater, C.S., Savelski, M.J. and Ruiz-Felix M.N. (2013), "Life cycle analysis of solvent reduction in pharmaceutical synthesis using continuous adsorption for palladium removal”, J Env Sci Health, Part A, Vol. 48 No. 13, pp. 1602-1608. http://doi.org/cxsd.

Slater, C.S. and Savelski, M. (2007), "A method to characterize the greenness of solvents used in pharmaceutical manufacture", J Env Sci Health, Part A, Vol. 42 No. 11, pp. 1595-1605. http://doi.org/bg2hjh.

Srai, J.S., Harrington, T., Alinaghian, L. and Phillips, M. (2015), "Evaluating the potential for the continuous processing of pharmaceutical products-a supply network perspective", Chem Eng and Proc, Vol. 97, pp. 248258. http://doi.org/f7z2t6.

Ulrich, Karl T and Eppinger, S. D. (2012), Product Design and Development, McGraw-Hill, New York.

Unger, C. (2013), Yttrande över Miljömålsberedningens delbetänkande "Minska riskerna med farliga ämnen" (SOU 2012:38) samt Kemikalie-inspektionens rapporter "Bättre EU-regler för en giftfri miljö” och "Handlingsplan för en giftfri vardag - förslag till åtgärder”, (Opinion on Environmental objectives council's interim report "Reduce risks of dangerous substances" (SOU 2012:38) and Swedish Chemicals Agency's reports "Better EUrules for a non-toxic environment" and "Action plan for a non-toxic living - suggestions for actions"), In Swedish.

Villamil, C., Nylander J., Hallstedt, S.I., Schulte, J. and Watz, M. (2018), “Additive Manufacturing from a Strategic Sustainability Perspective", In Proceedings of the DESIGN 2018 15th International Design Conference, Dubrovnik, 21st-24th May 2018, pp. 1381-1392.

\section{ACKNOWLEDGMENTS}

This work has been carried out with funding from Chalmers University of Technology Foundation, Knowledge Foundation, Vinnova and Blekinge Institute of Technology. This support is gratefully acknowledged. Sincere thanks to the industrial research partners. 